
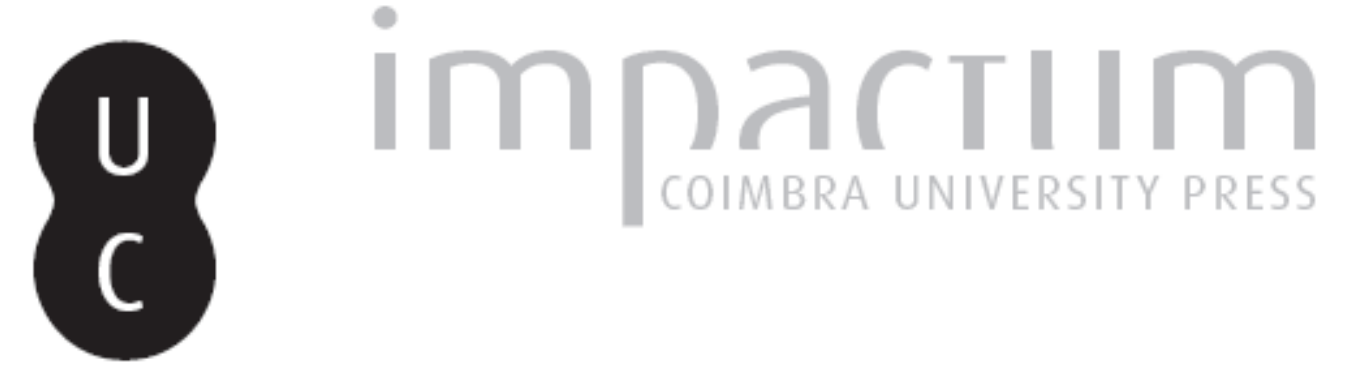

\title{
[Recensão a] BOTELHO, Maria Leonor - A Historiografia da Arquitectura da Época Românica em Portugal (1870-2010)
}

\author{
Autor(es): $\quad$ Campos, Maria Amélia Álvaro de \\ Publicado por: Centro de História da Sociedade e da Cultura \\ URL \\ persistente: \\ URI:http://hdl.handle.net/10316.2/39407 \\ DOI: \\ DOI:http://dx.doi.org/10.14195/1645-2259_13_25
}

Accessed : $\quad$ 26-Apr-2023 15:03:55

A navegação consulta e descarregamento dos títulos inseridos nas Bibliotecas Digitais UC Digitalis, UC Pombalina e UC Impactum, pressupõem a aceitação plena e sem reservas dos Termos e Condições de Uso destas Bibliotecas Digitais, disponíveis em https://digitalis.uc.pt/pt-pt/termos.

Conforme exposto nos referidos Termos e Condições de Uso, o descarregamento de títulos de acesso restrito requer uma licença válida de autorização devendo o utilizador aceder ao(s) documento(s) a partir de um endereço de IP da instituição detentora da supramencionada licença.

Ao utilizador é apenas permitido o descarregamento para uso pessoal, pelo que o emprego do(s) título(s) descarregado(s) para outro fim, designadamente comercial, carece de autorização do respetivo autor ou editor da obra.

Na medida em que todas as obras da UC Digitalis se encontram protegidas pelo Código do Direito de Autor e Direitos Conexos e demais legislação aplicável, toda a cópia, parcial ou total, deste documento, nos casos em que é legalmente admitida, deverá conter ou fazer-se acompanhar por este aviso.

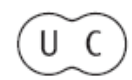



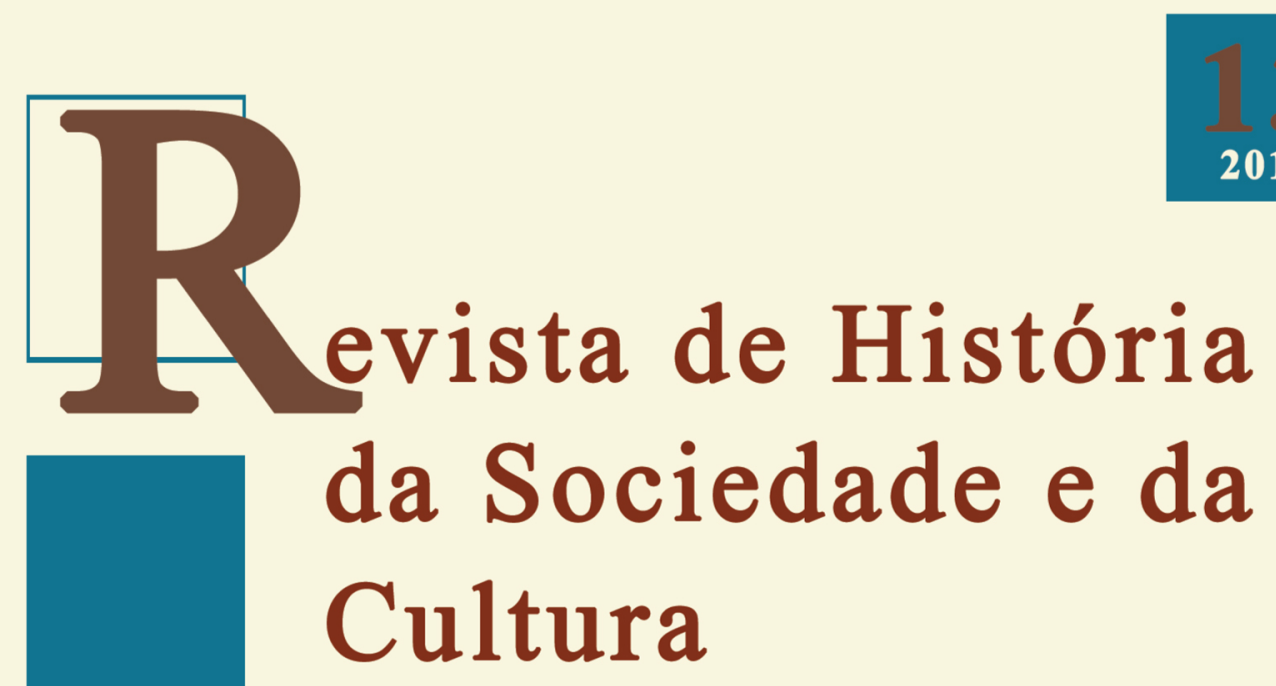

2013

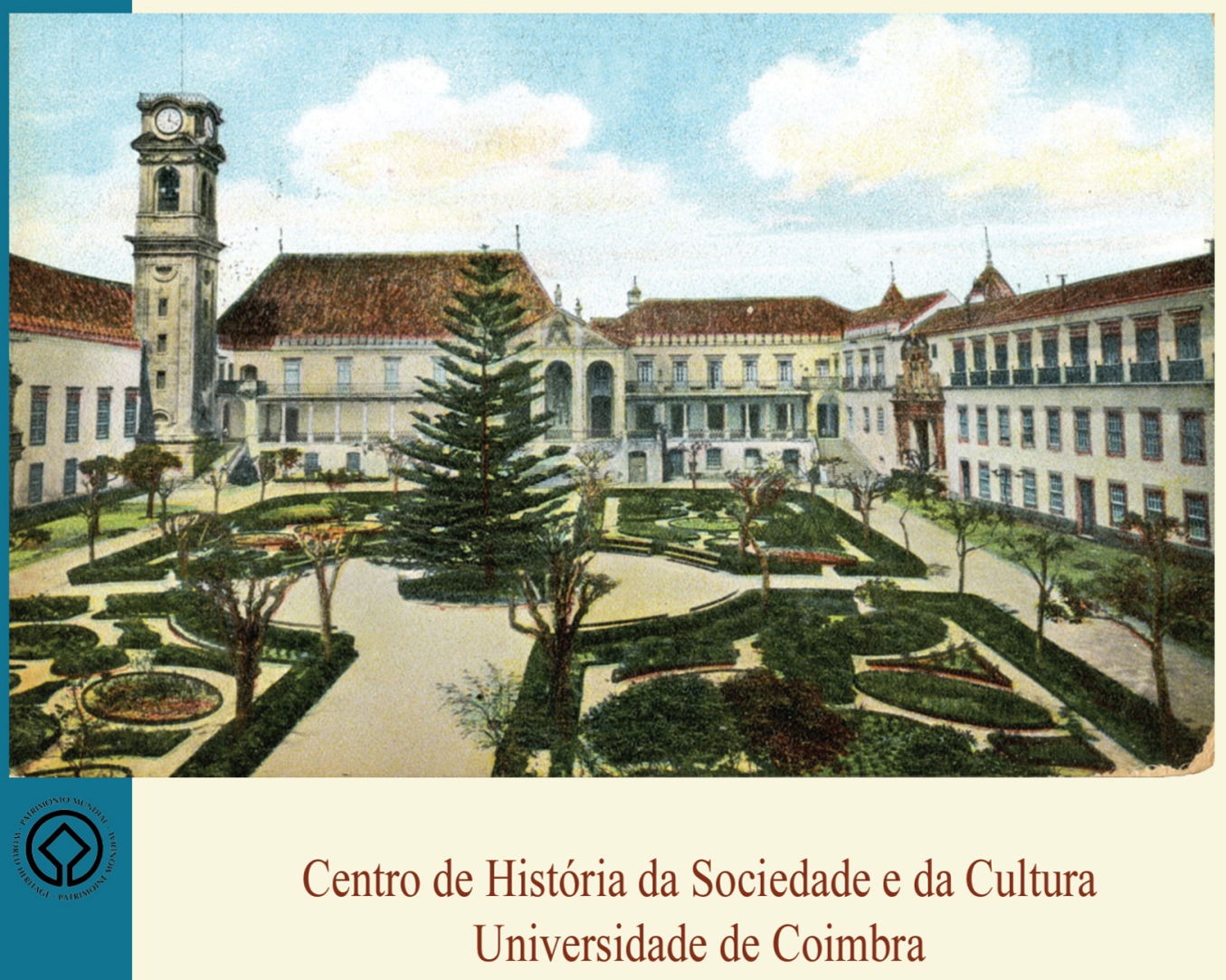

Coimbra 
artistas de uma nova geração de cantores, representantes das "modernas expressões da nossa música", atuaram no casino, quer em espetáculos a favor da Santa Casa da Misericórdia da Figueira, quer no $1^{\circ}$ Festival da Música Popular Portuguesa

Um terceira parte da obra, é dedicada ao edifício, aos seus espaços, programas decorativos, adaptações e readaptações. E a um capítulo final, intitulado "Amigos de estimação: a colónia balnear espanhola", no qual se evoca "Agosto, o mês das espanholas, o mês da alegria restolhenta e contagiosa, o mês que se vive sem se saber como, num estonteamento e numa vertigem", conforme transcrição do jornal O Figueirense, de 25 de setembro de 1935. São muitas os testemunhos na imprensa de manifestações de apreço da comunidade do país vizinho pela "mais linda praia portuguesa", com o Casino a organizar Las noches del Casino Peninsular.

Enfim, o Casino da Figueira, nas suas diversas configurações e fórmulas societárias que a administraram, foi um elemento central da atividade económica e social. A autora procurou, segundo afirma, identificar o contributo específico e singular de cada uma das empresas que a geriram e de captar a sua identidade como casino e casa de espetáculos na cidade da Figueira da Foz.

Eis um livro denso de informação, assente em escolhas criteriosas, de leitura agradável, com objetivos claramente alcançados, a ler com prazer e proveito não só dos figueirenses, mas sim de quantos se interessam pelo desenvolvimento local e sua explicação histórica, pela história das mentalidades e da cultura, pela história económica e social, pela história global.

Jorge Fernandes Alves

CITCEM/FLUP

jorge.falves@gmail.com

BOTELHO, Maria Leonor - A Historiografia da Arquitectura da Época Românica em Portugal (1870-2010), Lisboa: Fundação Calouste Gulbenkian e Fundação para a Ciência e a Tecnologia, 2013 (866 páginas).

Em Maio de 2013, no âmbito da colecção "Textos universitários de Ciências Sociais e Humanas", a Fundação Calouste Gulbenkian e a Fundação 
para a Ciência e a Tecnologia publicaram A Historiografia da Arquitectura da Época Românica em Portugal (1870-2010), de Maria Leonor Botelho. Esta obra corresponde à sua tese de Doutoramento em História da Arte, orientada por Lúcia Rosas, apresentada à Faculdade de Letras do Porto, defendida em Janeiro de 2011 e aprovada com distinção e louvor, por unanimidade.

O volumoso livro assim dado à estampa apresenta uma análise da produção historiográfica sobre a arquitectura românica, estudo que nos merece o maior realce, não só pelo seu carácter pioneiro, como também pela dimensão ampla do corpus que examina. Para o período assinalado, de cerca de 140 anos, é estudada a produção historiográfica de 25 autores, o que corresponde a 440 referências bibliográficas (artigos, teses, monografias e conferências) e ao tratamento de 259 estruturas arquitectónicas.

A obra divide-se em três partes. Antes de iniciar o estudo do referido corpus historiográfico, a autora dedica a primeira parte desta obra à "descoberta do estilo Românico". Assim, partindo da ideia de que "a designação atribuída a um dado estilo exerce uma profunda influência sobre a interpretação que dele se faz" (p. 13), a autora contextualiza a emergência deste conceito. Com vista à fundamentação do aparecimento da nomenclatura de Românico, começa por apresentar a, mais antiga, construção dos conceitos de Idade Média e de Gótico, explicitando as matrizes histórico-culturais que lhes deram origem, nomeadamente, em Itália e na Alemanha.

Ainda nesta parte, a autora dedica um capítulo à discussão levada a cabo, nos inícios do século XIX, por estudiosos franceses e ingleses, acerca da terminologia de romane ou romanesque. Aqui, a atenção do leitor é despertada pela apresentação desses autores - das suas diferentes proveniências geográficas e vivências culturais - e pela demonstração das repercussões da utilização de ambos os termos, no estudo da arquitectura românica. O desenvolvimento inovador desta problemática, por explorar no panorama da historiografia nacional, assenta, em grande medida, na leitura crítica que Leonor Botelho faz da obra de Tina Bizarro, estimulando-nos para a leitura de uma autora pouco divulgada na Europa.

De resto, com base numa leitura crítica e criteriosa da mais recente bibliografia sobre o tema, são apresentados os contextos historiográficos francês e inglês em que se definiu o conceito de românico, nos séculos 
XVII e XVIII. Deste modo, a autora traça o ambiente internacional em que se inseriu o início da valorização do estudo do Românico, em Portugal. Processo tardio, que a autora estabelece a partir de 1870, sendo que, até aí, entre nós, com o contributo de estudiosos estrangeiros como James Murphy e Francisco de Varnhagen, se reconheciam, na arquitectura medieval, tão-só, os estilos gótico e manuelino.

De seguida, na segunda parte da obra "Do conhecimento da arquitectura românica em Portugal", a autora apresenta a informação produzida no nosso país sobre o Românico (entre 1870 e 2010), em três vertentes: a escrita, a imagem, e o restauro. Metodologicamente, a análise da escrita segue a cronologia de publicação dos diferentes trabalhos, fazendo apontamentos críticos aos conceitos utilizados nos respectivos contextos de produção. Assim, 1870 é indicado como o ano da inauguração da historiografia do românico em Portugal, valorizando-se sobremaneira o contributo de António Augusto Gonçalves e de Augusto Fuschini. A época de afirmação da historiografia do românico seria, apenas, entre 1908 e 1918, período em que se destacam autores decisivos como Manuel Monteiro e Joaquim de Vasconcelos. Entre 1918 e 1955, Maria Leonor Botelho inscreve a golden age da historiografia do Românico em Portugal, na qual, tendo em conta as afinidades temáticas e ideológicas, apresenta dois grupos de autores: o "Núcleo do Porto" e o "Círculo de Coimbra". Deste período, realça a tendência, cada vez mais vincada, para a definição de um carácter científico e objectivo nos estudos de História da Arte. Logo de seguida, apresenta o intervalo estabelecido entre 1955 e 1966, atribuindo-lhe a construção de "um novo olhar" sobre o tema. Nele, constacta, por um lado, a diminuição dos títulos publicados, por outro, a superior qualidade dos mesmos e o aparecimento de novos autores. Por fim, estuda o período estabelecido entre 1966 e a actualidade, identificando-o com a compreensão da Época Românica, ou seja, com o ponto de chegada de um caminho que se vinha a traçar no sentido de uma perspectiva globalizante do conceito. Sublinham-se, neste momento, os trabalhos de José Mattoso, de Carlos Alberto Ferreira de Almeida, de Manuel Real, de Jorge Barroca e de Lúcia Rosas.

Sendo Maria Leonor Botelho uma autora da actualidade, das suas conclusões e da forma como apresenta este trabalho - desde logo o título - percebe-se a sua adesão à compreensão do Românico como uma época 
e, portanto, àquela última fase. Todavia, a sua investigação assenta numa abordagem distanciada dos vários contextos, resultando, assim, num estudo isento, claro e objectivante. Na sua análise, apesar de podermos reconhecer preferências, todos os autores são valorizados como actores relevantes no quadro cronológico em que actuaram.

Como já se disse, o estudo prossegue com a análise do conhecimento da arquitectura românica, através da imagem. Aqui, avalia-se o impacto da evolução da representação do Românico, inicialmente com base na gravura e, depois, na fotografia. Por fim, a autora problematiza o conhecimento do românico português através do restauro, estudando as intervenções da DGMEN, abordagem que lhe será cara desde a sua dissertação de Mestrado, na qual estudou os trabalhos realizados por esse organismo, na Sé do Porto 5 .

$\mathrm{Se}$, nesta parte do estudo, a autora segue metodicamente o aparecimento das diferentes publicações, reproduções iconográficas ou fotográficas e programas de restauro, num discurso, por vezes, demasiado esquemático porque norteado pelas respectivas cronologias de produção, imediatamente a seguir brinda-nos com relevantes ensaios, numa terceira parte consagrada aos temas e debates do românico português. Aqui, principia por problematizar a temática "Românico e Território", seguindo-se o estudo sobre a "Originalidade do românico português". No primeiro ponto, relevam-se questões como a paróquia românica, destacando-se especialmente o contributo de Carlos Alberto Ferreira de Almeida na sua definição de paróquia medieval e na sua compreensão da relação desta com o território; seguidamente, debate-se a relação do românico com a reconquista, apresentando a evolução do estilo a partir da construção ou da reconstrução de igrejas no território reconquistado. Neste último ponto, talvez esperássemos encontrar algumas linhas dedicadas à arquitectura militar românica, mas a opção da autora por não o fazer compreende-se face à amplitude do seu estudo e à profundidade com que problematiza o papel decisivo da arquitectura religiosa na reorganização do território.

Por fim, com vista à demonstração da originalidade deste estilo em contexto nacional, Leonor Botelho faz a sua classificação, apoiando-se nos

5 BOTELHO, Maria Leonor - A Sé do Porto no século XX. Lisboa: Livros Horizonte, 2006. 
trabalhos dos historiadores do românico português e salientando as especificidades geográficas, económicas, humanas e históricas que permitiram o aparecimento de particularidades locais. Ainda nesta última parte, debate o "Românico rural ou românico popular", enquadrando a existência, entre nós, sobretudo na região Norte e na Beira Alta, de um românico de resistência que perduraria até ao século XVI. Por fim, estuda as influências estrangeiras no românico português, sendo que também elas concorreram para a definição do seu carácter particular. No desenvolvimento dos temas e debates da corrente arquitectónica em questão, esta obra proporciona-nos um conhecimento minucioso e aturado do seu estilo e dos autores que o estudaram, bem como a compreensão de uma época nos seus mais diversos aspectos económicos, políticos e religiosos.

Como elemento complementar, a Historiografia da Arquitectura da Época Românica em Portugal conta também com uma base de dados Corpus Historiográfico do Românico Português - consultável em linha, no sítio www.marialeonorbotelho.com. Nela pode pesquisar-se toda a produção historiográfica que serve de fonte a esta obra. De acordo com as palavras da autora, o seu "conteúdo (...) é da exclusiva responsabilidade dos autores que desde 1870 foram escrevendo sobre o românico" (p. 679). Todavia, é ao seu trabalho que devemos a preciosa recolha, sistematização e disponibilização da informação. A base de dados em que sustentou a sua investigação constitui, assim, uma ferramenta, doravante, indispensável para o estudo, não só deste estilo arquitectónico, como também da época que o produziu.

Por tudo o que acima explanámos, pelos problemas que esta obra levanta, pelas respostas que dá, mas também por aquelas que deixa em aberto - desde logo, através das pertinentes ... que o seu texto apresenta - consideramos que o conhecimento de História da Arte Medieval e de História da Idade Média Portuguesa se fortaleceu com a apresentação desta tese, felizmente publicada e, agora, acessível ao grande público.

\section{Maria Amélia Álvaro de Campos melicampos@gmail.com}

